\title{
La saga des Vortex de Jean Métellus
}

\author{
Françoise Naudillon
}

(Paris)

Cette trilogie, composée des trois romans parus à ce jour La Famille Vortex (FV) (1982); L'année Dessalines (AD) (1987); Louis Vortex (LV) (1992) devrait bientôt s'enrichir de deux autres romans. ${ }^{2}$ Elle couvre pour l'instant le période 1949-1960. Elle met en scène le couple fondateur Solon et Olga Vortex, leurs enfants et leurs petits-enfants, dans une période tragique de l'histoire d'Haïti, après la chute du président Estimé. Ce dernier fut porté au pouvoir avec le révolution de 1946 soutenu par une junte militaire dont faisait partie le colonel Magloire. Ce fut cette même junte militaire qui le destitua en 1950 quand Estimé voulut obtenir la prolongation de son mandat présidentiel. Le 23 octobre 1950, Magloire devient président. Sa fin de règne est évoquée dans Jacmel au crépuscule. Après avoir tenté un coup d'Etat, il doit remettre le pouvoir à Joseph Pierre-Louis, président de la chambre de cassation, comme le prévoit la constitution, le 12 décembre 1956. S'en suivent dix mois de troubles où le pays est successivement dirigé par Franck Sylvain de février 1957 à avril 1957, par un conseil exécutif provisoire, puis du 25 mai 1957 au 24 juin par Fignolé, enfin par l'armée, un conseil militaire dirigé par Kebreau, jusqu'au 22 septembre 1957 ou François Duvalier est élu.

Tous ces événements, on s'en doute, n'ont pas été sans provoquer divers massacres et arrestation, départs en exil ou emprisonnements, suivant que l'une ou l'autre des parties en présence semblait devoir l'emporter. C'est cette toile de fond historique qui hante les romans de la saga des Vortex. ${ }^{3}$

Si les noms de ces hommes politiques n'apparaissent pas toujours dans les romans, les initiés savent reconnaître leur métaphore littéraire. Chercher à retrouver qui se cache par exemple derrière Jacky Maïxent, personnage d'industriel puissant et véreux, à l'origine du coup d'Etat qui porte Georges Férère au pouvoir dans FV, serait sans doute amusant pour les historiens. Mais l'auteur a voulu dans ces trois romans, démonter librement les mécanismes secrets de l'avènement de l'une des plus longues dictatures de ce siecle. Si la dimension historique de la saga des Vortex n'est pas à négliger, elle se double, comme dans les autres romans d'une étude sociologique rigoureuse, ici dans 
la capitale Port au Prince et dans l'ensemble du pays, et d'une parfaite maîtrise de l'intrigue et des personnages.

\section{Le traitement des personnages}

Autour du couple fondateur: Solon le patriarche d'ascendance africaine et Olga d'ascendance indienne, vivent les sept enfants du couple et leurs trois petits enfants: Edgar le militaire, époux de Martha et père de Wilfred et d'Ernest; Louis le professeur, époux de Myriam et père d'Yves-Solon; Joseph le prêtre; Ludovic le pharmacien; Sylvain le médecin, frère jumeau de Sylvie, professeur à l'école ménagère et fiancée de Paul Rétalix; Astrid, l'artiste, chanteuse et comédienne en exil depuis 1945.

«Vortex» est un mot du vocabulaire des sciences physiques qui signifie «tourbillon creux dans un fluide qui s'écoule.» Le choix de ce nom de famille est dâ a la femme de Jean Métellus, lequel cherchait un nom à consonnance indienne. Les noms indiens, comme on le voit dans Anacaona, le nom de la première pièce de thêatre écrite par Jean Métellus, ${ }^{4}$ sont souvent terminés par le suffixe -ex. Vortex, mot de la langue française, permettait de garder cette parenté homophone avec les mots indiens, tout en symbolisant le destin de cette famille condamnée par le tourbillon des événements politiques et historiques en Haïti, à l'exil.

Le premier roman La famille Votex, montre en effet comment successivement Edgar le militaire, Louis le professeur, Paul Rétalix et Sylvie, Sylvain président éphémère d'Haïti et enfin Joseph devenu évêque, sont contraints de partir à New York ou à Paris, sous la pression implacable des événements. Dès les premières pages du roman, la famille réunie autour d'un repas de Noël, regrette l'abscence d'Astrid.

«L'exil n'est point d'hier, l'exil n'est point d'hier,» murmure Edgar, l'ainé des Vortex. Jean Métellus explique le sens de cette litanie:

Je crois qu'Edgar fait allusion à ses origines. A l'origine de sa mère qui est la dernière descendante indienne de la république d'Haïti et qui se sent exilée dans son propre pays puisque ses ancêtres ont été anéantis. Il fait également allusion à son origine africaine, car tous les Haïtiens sont africains et occupent un pays qui ne leur appartient pas, un pays où ils ont été transplantés. Edgar fait allusion à ce double exil. ${ }^{5}$

L'année Dessalines, roman situé en 1960, est dédié au personnage de Ludovic Vortex, le seul enfant de Solon qui soit resté au pays. A propos de L'année Dessalines, Régis Antoine écrivait:

[...] il est difficile de mesurer à deux cents ans de distance le formidable impact de la révolution de Saint Dominigue, les pivotements textuels qu'elle suscita dans les oeuvres écrites à chaud, la matrice toujours féconde et fondatrice qu'elle constitua 
pour des oeuvres dont la dernière en fait est L'année Dessalines de Jean Métellus. ${ }^{6}$

Le troisieme roman de la saga, Louis Vortex, conte l'histoire du personnage homonyme qui vit en exil à Paris.

\section{L'art du portrait}

Un inventaire rapide des personnages de la saga nous permet d'en compter plus de trois cents, dont chacun, esquissé ou plus fouillé psychologiquement, participe de l'évocation de cette société haïtienne ou européenne, comme dans Louis Vortex. L'originalité de la présentation des personnages chez Jean Métellus, vient de l'extrême précision, une précision clinique, du portrait physique: «Née le 11 juillet a Fonds des Blancs, dans le sud-ouest de la république, Olga Bartel mesurait un mètre soixante et pesait soixante douze kilos» (FV, 24).

Les traits du visage sont une indication précieuse de la psychologie du personnage:

Son nez épaté et court laissait deviner un odorat bien développé, il surmontait une énorme moustache que compensait peut-être sa calvitie précoce et sur laquelle, faute de cheveux, le barbier s'attardait car papa Solon s'obstinait à l'appeler tous les mois. De très petites oreilles - mais l'oüe fine - des lèvres charnues et bien dessinées, des yeux mobiles et vifs, complétaient un visage ouvert et amical (FV, 16).

Métellus s'inspire aussi d'une conception balzacienne du personnage, qui évolue dans un milieu, un décor, lequel l'explique et le prolonge.?

Les nombreux coussins, la couverture un peu délavée d'un divan trahissait le plaisir que prenait parfois la maîtresse de maison à $s^{\prime}$ allonger pour se détendre [...] C'est dans ce lieu que vivait Clivia Chamfort depuis cinq ans [...] Une harmonie parfaite semblait régner entre la propriétaire, les meubles, les livres, les murs (AD, 61).

Chaque personnage de la saga est parfaitement individualisé et les subtilités de sa psychologie finement analysées:

Saturé de cauchemars, d'envies insensées, entouré par les bruits torturants et trompeurs del'exil, envahi par uneagitation factice, en trompe l'oeil, Louis tentait de conserver son intégrité, sa cohérence. L'inquiétude l'amoinindrissait si visiblement, le déprimait si entièrement, si sournoisement, qu'il croyait obéir à un appel $(L V, 65)$. 
La psychologie des personnages évolue, Yhomme n'est pas figé dans une attitude ou un comportement. Les personnages sont souvent doubles: Edgar, le militaire, homme d'ordre et de fidélité, est comme son père Solon, un poète. S'il est militaire, Edgar peut être aussi suceptible, jouisseur, généreux ou impitoyable. Joseph le prêtre, quant à lui est soupçonné d'avoir connu l'inceste avec sa soeur Astrid:

La moindre allusion, une simple remarque de Joseph sur le sort d'Astrid prenait l'allure d'une confidence déguisée: d'après sa famille, il était le seul à recevoir de ses nouvelles. Les liens que les unissaient étaient si intimes, si orageux, qu'on avait fait dépendre l'exil de l'une et le sacerdoce de l'autre d'une certaine complicité (FV, 23).

Louis le professeur, qui a une réputation de coureur de jupons, est aussi un homme de convictions, ardent défenseur du président Estimé. Il prononcera un discours de soutien au président, ce qui lui vaudra de devoir partir en exil à la chute de ce dernier.

Mais c'est dans Louis Vortex que l'on trouve la plus complète étude de l'évolution psychologique d'un personnage. La souffrance profonde née de l'exil, crée un bouleversement des valeurs et des repères. Ces sentiments subtils sont traités par le narrateur qui sait rendre pour le lecteur l'intimité de ces mouvements de l'âme:

La viele pourchassait; cette vie à laquelle il avait offert le sacrifice de l'exil, le déportait de nouveau, le plaçait devant des choix multiples. Irrémédiablement écartelé entre l'acceptation et la fureur, la fuite ou la résistance, expulsé de lui-même, émigré de l'extérieur comme de l'intérieur, sans point d'ancrage, Louis se trouvait déchu de ses droits naturels, enchaîné à l'immuable galère de l'existence individuelle, trahi par ses propres forces, étranglé par son imagination. La nuit lui composait un visage de pénombre, lui assignait des limites indiscernables, l'entrainait dans le tourbillon du désir jamais comblé, des voeux défaits à peine proférés $(\mathrm{LV}, 67)$.

Louis passera de l'engagement militant chrétien à l'engagement communiste avant de trouver sa voie, dans la défense d'Haïti, de sa mémoire et de son avenir, dans l'écriture, tout en se ressourçant au contact de sa famille à qui il demande de le rejoindre en exil.

Ludovic Vortex, le plus mystérieux des membres de cette famille, le plus maladif, est ainsi décrit:

Le dos légèrement voaté, il se déplaçait à petits pas pressés; sa carrure étroite contrastait avec la longueur de ses bras au bout desquels pendaient des mains décharnées au doigts maigres et fins mais toujours soignés (AD, 24). 
Dans L'année Dessalines, qui évoque 1960 - date de commémoration choisie par les personnages, pour honorer l'homme qui proclama l'indépendance haïtienne - et les amours de Ludovic Vortex et de Clivia Chamfort, le dernier des Vortex apparaît comme un personnage froid et peu soucieux des autres. Contrairement à la technique employée dans Louis Vortex la psychologie de ce personnage est traitée de l'extérieur, l'homme est défini par ses gestes et son comportement. Le point de vue narratif est investi par un personnage du roman, ici Richard Felicissime. Celui-ci vient de perdre son emploi de professeur pour des raisons politiques et s'epanche aupres de son ami:

Quand il parlait à Ludovic de ses difficultés matérielles, il avait toujours l'impression de se confier à un arbre tant son ami restait imperturbable [...] La timidité de Ludovic l'empêchait de manifester son émotion, sa sympathie, mais il proposait de bon coeur à son ami de partager la tasse de chocolat dont il se contentait $(A D, 25)$.

Ludovic proposera par la suite à Richard de prendre la gérance d'une pharmacie avec un salaire supérieur à ses honoraires de professeur.

C'est ainsi que, par des notations trantôt explicites, tantôt suggérées, les personnages de Jean Métellus gagnent une véritable densité humaine. Mais ce qui caractérise le mieux l'originalité du traitement des personnages, ce sont les 'crises psychologiques' au cours desquelles, l'être profond semble se défaire.

\section{La crise ou la gestion de l'angoisse}

La crise survient toujours à un moment de tension créé par un événement soudain et dramatique. La violence longtemps contenue par le personnage, cette violence permanente dans laquelle baignent les romans de la saga, se retourne contre l'homme ou la femme qui en est le siège et peut créer des désordres physiologiques irréparables. Les femmes, plus que les hommes sont touchées par ce phénomène. Dans FV, la haine entre les belles-soeurs trouve brutalement à s'exprimer à la naissance de l'enfant de Louis et de Myriam, Yves-Solon. Martha, la femme d'Edgar, dans un moment de folie, blesse la mère et l'enfant. Cette scène de violence familiale est aussitôt interprétée comme une métaphore de toute la société haïtienne:

Quant à nous témoins de ces scènes, nous pensons aux conséquences funestes des débordements de pouvoir, à leur genèse dans la canaillerie des uns et la criminalité des autres. La société a fait de Martha la belle, une femme cruelle à l'abri de toute justice et de Myriam, l'humble fille d'un pêcheur, une victime toute désignée à l'incontinence d'un trop plein de puissance (FV, 33). 
Dans L'année Dessalines, Madame Chamfort, mère de Clivia, issue d'une riche famille mulâtre, fait une crise d'aphasie brutale à l'annonce des fiançailles de sa fille avec Ludovic Vortex, un Noir.

La crise, signe paroxystique de l'angoisse intérieure, peut surgir brutalement, sans rien qui la prépare. Après une conversation paisible avec ses frères et soeurs sur l'avenir de l'église haïtienne (FV, 170), le père Joseph Vortex s'effondre, victime d'une crise de larmes, terrassé par l'angoisse de l'avenir. Les bourreaux les plus impitoyables euxmêmes, ne semblent pouvoir y échapper. Dans L'année Dessalines, Arcady Willy, l'homme des basses ceuvres connaît un moment d'angoisse mystique avant d'accomplir sa sinistre mission de grand ordonnancier de l'exécution des membres du «complot» dénoncé par le président. La crise que subissent certains personnages, cet effondrement pathétique, dit mieux que le récit des émeutes et des massacres, l'état naturel de violence et de peur dans lequel est plongé le pays.

La crise symbolise surtout le pouvoir d'une dictature dans l'intimité d'un peuple: «Tout Haïtien est prisonnier, dit Jean Métellus. Privée de parole, sa vie intérieure est menacée d'étouffement.»8

Les familles claniques offrent un abri faussement protecteur contre la violence.

Les clans familiaux

On distingue trois grandes familles dans la saga des Vortex. La famille Vortex, la famille Chamfort, la famille Villejoint. En schématisant, ces familles qui par endroits fonctionnent comme des personnages à part entière, sont chacune symbole de l'état de la société haïtienne. La Famille Vortex, a la fois descendante des Indiens et des Noirs d'Afrique symbolise les racines profondes et légitimes de la nation haïtienne. La famille Chamfort représente la minorité mulâtre. La famille Villejoint représentequantà elle, les parvenus aux origines mêlées que gravitent autour du pouvoir.

La famille Vortex est représentante de cette petite bourgeoisie noire qui aspire à avoir sa part de pouvoir politique et de richesses. Solon le patriarche, pratique le métier d'usurier de façon plus honnête que ses confrères, quant à ses fils et à ses filles, ils symbolisent ce que Jean Métellus appelle, «l'on du pays: «L'or symbolise les facultés intellectuelles. Ce que le pays avait de plus précieux, ce qui pouvait l'aider non pas a s'enrichir, mais seulement à vivre.»"

Commes les autres familles de la saga, elle fonctionne avec un système d'alliance, de parents, d'amis et d'alliés, enfants légitimes ou non, qui lui permet d'entretenir un réseau d'information dans toute la société. Car les domestiques font partie du clan familial et quelquefois contribuent à son agrandissement. Ainsi Rolande, la gouvernante du pere Joseph dans FV, deviendra la mâttresse de Ludovic dans $\mathrm{AD}$. Ils auront un fils: Kléber. La famille se caractérise par sa fécondité. Les femmes ont des enfants en grand nombre, de même que les hommes, dans ou hors du mariage. Ces rameaux secrets de l'arbre familial permettent de s'assurer protection même quand publique- 
ment on appartient à des camps politiques opposés. La famille Vortex jouit dans la saga d'un destin singulier:

Le vent est roi dans le monde comme l'arbre dans la forêt

Avec son balancier dans la bouche

II souffle sa folie dans le corps des Vortex

Tout le pays tourne et tourbillonne entre ses mains

la bourrasque répétée mène à la tourmente

La tourmente qui gronde et qui fait craindre la tempête

Une tempête sans pitié, comme un cyclone

Astrid est comme l'attaque de la tempête

Je demande grâce pour Ludovic (FV, 50-51)

prédit la tante d'Olga Vortex, Irène. Cette prophétie illustre le choix du nom Vortex pour cette famille décimée par l'exil. De même est annoncé que Ludovic sera le seul des enfants à pouvoir rester au pays.

Par contraste, la famille Chamfort, symbole de cette riche bourgeoisie mulâtre que l'on découvre dans $\mathrm{AD}$, vit sous le sceau du secret. Secret des malversations criminelles commises par un oncle de Clivia, Quentin Chamfort, alors même que cette famille présente une façade toute d'honorabilité.

Les Chamfort se disent issus d'un médecin nantais qui parvint en Haiti dès 1804 et aurait été le médecin de Dessalines. Rejeton de la bourgeoisie française éclairée, cet ancêtre nantais serait l'un des quelques blancs de l'époque à bénéficier d'une carte d'identité haïtienne..$^{10}$

Les Chamfort sont riches, ils possèdent une maison à Pétionville, impasse Schoelcher, et une habitation a Léogane où se pratique la polyculture. La famille se vante d'avoir toujours eu un de ses membres partie prenante dans l'histoire du pays. Le grand pere de Callisthène, père de Clivia, avait crée dès 1830 un musé à la gloire du Nantais son père. Lui-même était le fournisseur de papier du Journal officiel et du Moniteur crée en 1845. La seule ascendance nègre que les Chamfort avouent est celle $d^{\prime}$ Esther Pierrette, la grand-mère paternelle.

L'écrivain prend plaisir à détailler l'histoire de cette famille à travers laquelle on peut mieux comprendre l'état des forces en présence dans le pays. Le personnage de Quentin Chamfort, demi-frère de Callisthène le notaire qui s'est efforcé d'en effacer toutes traces, permet de comprendre que la richesse de la famille est d'origine criminelle. C'est en devenant créancier de l'Etat que l'oncle Quentin a bâti sa fortune. L'histoire des malversations auxquelles se prêta ce personnage explique en partie l'extrême misère dans laquelle vit le peuple haïtien. L'évocation de ce personnage permet de mieux comprendre les mécanismes d'accaparement des biens et des capitaux publics par des particuliers. Notons que si Solon Vortex est l'usurier de Saltrou, Quentin Chamfort fut l'usurier de l'Etat. Il ne s'agirait que d'une question d'échelle. Les circuits de l'argent sont minés.

La famille Villejoint, liée aux Chamfort par le mariage de Sophie Villejoint avec Charles Chamfort, est l'une des plus originales créée par Jean Métellus. La mère, Octavie 
Villejoint est officiellement la voyante du président. Elle a du reste connu une jeunesse tapageuse et sa réputation de nymphomane est bien établie. Aucun de ses enfants ne serait de Johanes, son époux, mais de plusieurs hommes que la rumeur désigne: Sophie serait la fille d'un marin américain de passage, Teddy Villejoint, le lieutenant colonel rival de Ludovic Vortex, le fils du poète Aurèle Baudoin. Les frères de Teddy seraient respectivement fils de Paul Bastian, le haut fonctionnaire des postes et de Callisthène Chamfort. Quant au dernier, il serait le fils de Lazare Félicité, le professeur. Les filiations chaotiques de cette famille lui permettent de bénéficier des protections de divers milieux. Mais la proximité avec le pouvoir est chère payée. Octavie, la mère, se voit contrainte de dénoncer un complot et aura une responsabilité dans la mort de son propre fils.

\section{Les femmes}

Les personnages de femmes abondent. La séduction de la femme peutêtre dangereuse. Ainsi le personnage de Raymonde dans FV, cousine de Martha, symbolise le pouvoir de séduction trouble de la femme:

Esthéticienne d'une trentaine d'années, de taille moyenne, elle exerçait un attrait magnétique sur les deux sexes: ses yeux étincelants, ses fossettes, ses lèvres pulpeuses séduisaient l'homme, réveillaient sa sensualité et l'incitaient à chercher auprès d'elle détente et plénitude; ses mains adroites et souples, son visage délicat, patient et doux, favorisaient les confidences de la femme. Elle avait désuni bien des couples (FV, 52).

Si Martha est un personnage de femme fascinant comme peut l'être un serpent, Olga Vortex symbolise la maternité digne, triomphante et fière:

Ses yeux de velours dont un hypnotiseur aurait pu tirer avantage, ses sourcils, ni trop minces, ni trop épais, parfaitement dessinés sans le secours d'artifice ou de fards, ses cheveux soyeux et lisses, d'un noir dejais, avaient ébloui Solon; sa coiffure en chignon, et les grands anneaux d'or qui ne quittaient jamais ses oreilles d'ailleurs assez larges lui donnaient un profil austère, sévère, tendu $(\mathrm{FV}, 25)$.

Les femmes sont généralement rondes, appétissantes, elles se caractérisent par leur regard, leur allure. Elles inspirent chez l'homme, qu'elles soient d'Europe ou d'Haïti un désir gai:

Agée de vingt ans, brune, tout à la fois épanouie et mignonne, vêtue légèrement en raison de la chaleur, d'une robe bleue transparente qui laissait deviner l'absence de soutien gorge [...] Chaque fois qu'elle déposait le pied à terre ou faisait un geste ses 
deux seins dansaient en un mouvement gracieux dans lequel

Louis n'hésitait pas à voir une bénédiction de la nature (LV, 114).

Métellus dresse d'autres portraits de femmes intellectuelles comme Clivia Chamfort ou comme Nadine, la psychologue, amie de Louis Vortex en France. Les femmes sont aussi des auxiliares du pouvoir: ainsi le personnage de Malvina dans $A D$, prostituée et indicatrice, elle est à l'origine du guet-apens qui condamnera à la mort plusieurs jeunes militaires.

Certaines de ces femmes inspirent même de la répulsion.

Agée d'une cinquantaine d'années, quarteronne presque blanche, Edwige Pirval se maquillait avec démesure à tel point qu'on la croyait d'une propreté douteusealors qu'elle se baignait deux fois par jour ... Ronde et dotée d'une poitrine opulente qui défiait les soutiens-gorges du commerce, la malheureuse devait les commander sur mesure. Ses hanches fortes, ses jambes comme deux poteaux, ses chevilles massives surmontant deux petits pieds ... Dans cette figure large, un petit nez surmontait deux lèvres pourpres comme la pulpe d'une grenade (FV, 206207).

Edwige Prival est à l'image de cette société décadente et corrompue, couverte d'un masque d'apparence qui gravite autour du régime. Elle donne le ton de vulgarité satisfaite qui sied à un tel milieu. Comme Octavie Villejoint, dans $A D$, les femmes aident leurs maris à maintenir leurs positions et leurs petits avantages. Telle $\mathbf{n}^{\prime}$ hésitera pas à coucher avec un ministre pour favoriser la carrière de l'époux, telle autre remerciera le supérieur militaire de son mari en nature.

\section{Inventaire d'une société}

C'est avec un regard tantôt ironique que l'auteur se fait le chroniqueur impitoyable d'un corps social en voie de déliquescence et de décomposition. L'écrivain excelle dans la description de ces cérémonies mondaines où les haines se nouent, les conspirations se préparent et où règne la peur. On en trouve plusieurs exemples. Ainsi la cérémonie d'intronisation de Joseph Vortex, évêque d'Haïti: «Les invités affectaient de fêter uniquement la nomination du père Vortex; à la vérité ils souhaitaient surtout prendre le pouls de la situation politique. Le pays tremblait...» (FV, 205).

Le morceau de bravoure de ce type de cérémonie - on dirait sacrificielle - se trouve dans le premier chapitre de L'année Dessailines où le premier janvier 1960, au siège de la SNAD, se fête l'anniversaire de la proclamation de l'indépendance. Ostentations et vanités, inquiétudes vagues, propos mondains... Les ministres se succèdent, se demandant si leur présence sera bien vue du pouvoir. Les patronymes de ces hommes d'Etat dénoncent la volonté ironique et caricaturale de l'auteur: Gustave Belhumeur (minstre de l'éducation et des cultes), Wilfried Ladouceur, sous-secrétaire d'Etat, Théo- 
dore Beaufront, directeur de cabinet... le tout sous le regard inamical d'un Arcady Willy, l'homme des basses oeuvres. Si les intellectuels présents à cette soiré décident de consacrer l'année 1960, année Dessalines, cette audace déclenche aussitôt chez eux l'angoisse du rapport de police.

\section{Les intellectuels}

Ils apparaissent principalement dans L'année Dessalines. Le destin de Richard Felicissime, professeur, ami de Ludovic Vortex, en est un exemple. II perd son poste, comme Louis Vortex dans FV pour des raisons politiques. Pourchassés, surveillés, les intellectuels parlent longuement de l'Etat du pays. Mais l'action leur est rarement possible. Dans cette société où toute pensée est interdite, la solution reste l'exil, ${ }^{11}$ car le pouvoir ne craint rien tant que l'union de la force (l'armée) et de l'intelligence. Les mouvements étudiants, comme l'UHEH, plus militants, à l'origine des nombreuses grèves générales qui paralysent le pays sont comme les manifestants, mâtés dans le sang (AD, 76-83). Lazare Félicité, professeur de droit, voit sa femme tuée sous ses yeux.

Le président, dans $A D, a$, quant à lui, une vision toute particuliére et personnelle des intellectuels.

Ils y a trois ordres d'intellectuels: les illuminés qui ne sont bons qu'à semer le désarroi car ils n'ont la responsabilité de rien, qui parlent de Dessalines en ignorant que je suis moi-même Dessalines ou une sorte de quintessence dessalinienne; les intellectuels de terrain et de bons sens, les hommes pratiques comme moi, ceux qui se sacrifient pour une grande cause pour l'arène ou la gaguère, ${ }^{12}$ ceux qui ont sacrifié une grande ambition personnelle pour devenir sauveur de gueux indécrottables; ceux qui veulent transformer un peuple de mendiants en héros et qui ont trouvé leur modèle en moi; et enfin des intellectuels de parade, des agitateurs à la petite semaine qui savent à peine lire et écrire, incapables de prendre la direction d'un peuple ou la charge d'un Etat (AD, 262-263).

Le président dans $\mathrm{AD}$, sous les traits duquel on pourrait reconnaître François Duvalier, se définit lui-même comme le premier intellectuel du pays.

Voyez-vous, Lazare Félicité est le type même d'intellectuel que je n'aime pas. Quand il parle de Dessalines, on finirait par croire qu'Haïti n'a enfanté que ce héros. Où suis-je dans tout ça? Dessalines, je veux bien. Mais moi? [...] Non, il ne faut pas parler ainsi devant moi qui suis l'une des plus grandes intelligences politiques de ce siècle $(\mathrm{AD}, 75)$. 


\section{Le peuple}

Le ton change. La peinture de ce petit peuple des villes et des champs qui souffre avec courage et dignité est remplie de poésie et de ferveur: ${ }^{13}$ «L'une [les paysannes] portait un plateau de bois chargé de fruits, une autre marchait, une main sur la hanche, un panier sur la tête, un foulard multicolore autour des reins» (FV, 83).

Ce peuple de paysans constitue l'âme haïtienne. Dans les villes aussi, la misère règne. Le quartier Bolosse exhibe ses plaies:

Les enfants de la cinquième avenue Bolosse déchargeaient leur lance-pierre sur les pigeons de plus en plus rares. [...] Dans ces quartiers, poules et coqs étaient habituellement attachés aux pieds des arbres [...] Les mères attendaient avec impatience le butin pour donner un peu de goût à l'inévitable millet ou maïs du midi et du soir (FV, 171).

Les domestiques nombreux qui servent dans les familles de la saga des Vortex, constituent un contrepoint fécond aux discours des maîtres avec lesquels ils vivent dans une harmonie patriarcale. Les conversations, commentaires, proverbes qu'ils prononcent sont une source de sagesse et de philosophie. Tambour, le jardinier de Ludovic Vortex ou Damien, garçon de course d'Edgar Vortex, originaire de Port de Paix, sont à leur manière des héros anonymes: le premier pour sa sagesse (ne sait-il pas reconnaître d'un coup d'oeil une femme enceinte de quelques semaines?), le second pour son engagement, parcours exemplaire d'un homme du peuple courageux, s'opposant à la puissance d'un militaire sanguinaire. Mais ce qui fait la force de ce peuple, c'est sa dimension spirituelle.

\section{L'église et le Vaudou}

Ces deux forces sont omniprésentes.

Le Vaudou apparaît comme une religion nationale. Comme le dit Bernard Mouralis: ${ }^{14}$

[...] les formes traditionnelles d'origine africaine se modifient [...] elles intègrent certains éléments du christianisme; elles réunissent d'autre part, dans un même ensenble religieux, les éléments culturels empruntés à des régions différentes de l'Afrique et, par un mécanisme complexe, elles finissent par s'imposer à la population de tout un pays, devenant par là des religions «nationales» dont le Vaudou haitien constitue un exemple caractérisé.

La nomination de Joseph Vortex, évêque d'Haïti est l'occasion de dresser rapidement dans FV, l'histoire du clergé. Si Louis Vortex, en exil en France croit en un véritable engagement chrétien, l'auteur reste pessimiste quant à la sincérité de l'église. Tiburon, l'ancien garçon de course de Ludovic dans $A D$, a pris le nom de «Dieu seul sauveur» 
mais se retrouve chassé de l'église où il s'est réfugié par les prêtres et la police qui n'admettent pas que les miséreux dorment dans l'église.

En revanche la spiritualité Vaudou imprègne toute la sociéte. Le pouvoir s'en sert parfois comme d'un instrument:

[...] on dit que Duvalier a pris le pouvoir avec le vaudou. Mais ce n'est pas vrai du tout. Duvalier s'est servi du vaudou pour tromper tout le monde [...] il a utilsé les prêtres du vaudou comme il a utilisé les prêtres de la relgion catholique, ${ }^{15}$

explique Jean Métellus. Sur le plan littéraire, le président dans AD est atteint d'un véritable délire mystique où les chiffres semblent avoir une force ésotérique et lui permettront de décider du nombre des hommes qu'il exécutera suite au complot imaginaire. Les hommes proches du pouvoir comme Ladouceur sont présentés comme étant à la fois vaudouisants et franc-maçons.

Solon Vortex, dans AD est salué du titre de Papa Legba. C'est grâce à un rêve mystique vaudou que Louis Vortex, en exil en France, sortira de son marasme psychologique:

Cette nuit-là, Louis fit un songe: un nègre de fière allure, aux dents écarlates, un mouchoir rouge à chacun de ses poignets, ceignit sa tête d'un foulard vermillon puis brandit devant lui un drapeau en fumant un cigare et lui réclama du rhum selon la formule consacrée "grainn mren frètt» $(L V, 59)$.

Le personnage donnera à Louis un message aux interprétations multiples: «ce que tu es tiens ce que tu hais» où l'homophonie «es,» «hais» donne toute l'ambiguitté. Ce n'est qu'après avoir interprété ce message que Louis trouvera sa voie en exil. On le voit, la mystique vaudou impreigne tous les romans de la saga des Vortex.

\section{L'armée}

Les militaires ont deux représentants emblématiques dans la saga: Edgar Vortex dans FV et Oscar Villejoint dans AD.

Les militaires représentent la seul force organisée du pays. Ce sont des juntes militaires qui mettent au pouvoir ou démettent les présidents, comme le montre par exemple, dans la récente histoire haïtienne, l'éviction du président démocratiquement élu, Jean-Bertrand Aristide ${ }^{16}$ par le général Cédras.

L'armée constitue une force de répression intérieure lors des manifestations civiles. Mais plus qu'au fonctionnement de l'armée comme corps, l'auteur s'est efforcé de décrire de l'intérieur le parcours de certains de ses membres. En donnant, dans AD, la biographie de jeunes gens issus du pays profond comme Bergamotte, Sans-Nom, Lenfer, Faveur ... et les raisons qui les ont poussés à s'engager, en montrant les alliances que nouent les militaires entre eux (voir les rapports dan AD entre Villejoint et ses deux 
lieutenants Latremblé et Soliman), entre l'argent et l'armée (voir les rapports entre Oscar Chamfort, le banquier et Soliman et Vidargent, parrains de ses enfants) le romancier rend plus perceptibles les courants de rivalité et d'ambition, les rapports de force et de conviction qui traversent l'armee.

L'armée est loin d'être un bloc monolithique. Les complots qui émaillent la saga des Vortex, sont pour la plupart préparés par les militaires. Un exemple en est donné dans FV. La préparation du complot qui portera Férère, le ministre de l'intérieur, au pouvoir:

\begin{abstract}
A Pétionville, entre-temps, s'étaient réunis le colonel Pirval, chef d'Etat-major, le colonel Paquito Felix, chef de la police, le lieutenant colonel Ralph Oswald, comandant du bataillon Dessalines, le major Quentin Samuel [...] et le major Thierry Steven, chef de service spécial du commandant du centre d'instruction (FV, 69).
\end{abstract}

C'est l'alliance des militaires et de l'argent, représenté par Maïxent, l'industriel import-export, prévaricateur des biens publics, le tout avec la caution bienveillante de l'église représentée par Monseigneur Le Croutonnec, qui permet l'arrivée au pouvoir de Férère dans FV. Ce schéma, avec des variantes, est immuable.

Dans FV, les mêmes se réuniront pour démettre Férère et le remplacer par Sylvain Vortex, dont le modèle est sans doute Fignolé, président d'Haïti pendant 57 jours. Le cynisme des militaires tient dans ce propos de Thierry Steven:

Je propose qu'on lui donne le pouvoir et que nous autres militaires restions en dehors de l'affaire pour ne pas perdre notre prestige. Nous resterons les bras croisés... et les mains pures. Pendant qu'il commence à s'organiser, nous aurons le temps de préparer sa chute $(\mathrm{FV}, 238)$.

Loin de donner une vision caricaturale de l'armée (Villejoint dans ADet Edgar Vortex dans FV sont les représentants d'un certain honneur militaire), le romancier s'efforce de montrer les contradictions de ce corps dont la mission n'est pas de défendre le pays mais les intérêts des cliques au pouvoir.

\title{
Inventaire du pouvoir
}

Plusieurs figures d'hommes parvenus au pouvoir suprême sont évoquées. Sylvain Vortex en est un exemple:

On trouve chez lui deux dimensions. Le goût du pouvoir, parce que très tôt après ses études de médecine il s'est engagé dans la politique. L'ambition aussi. Mais il y a chez lui un certain amour du peuple. Quand on examine sa vie, on se rend compte qu'il n'a jamais utilisé ses connaissances pour s'enrichir comme le font la plupart de médecins en France, aux Etats-Unis ou à Haïti. Il fait 
preuve de dévouement, d'esprit de sacrifice. Le fait-il pour gagner en crédibilité, en tant qu'homme politique? Je ne le sais pas. Jusqu'ici, il me semble sincère, ${ }^{17}$

dit Jean Métellus parlant de son personnage. Dans AD, la figure du Président est l'une des plus réussie, personnage baroque et sanguinaire, il n'est pas sans rappeler les portraits de dictateurs dressés par un Alejo Carpentier ou un Miguel Angel Asturias. ${ }^{18}$

Autour du pouvoir, gravitent des personnages tous aussi contrastés. Fulbert Giraud parle de son travail:

[...] mon boulot, tu ne le comprends pas, c'est mâcher jour et nuit la parole des autres, la distribuer en y croyant et la vomir sur ordre. ... Mâcher et vomir les pensées d'autrui, c'est mon boulot (FV, 108).

Outre les indicateurs de police ou les tortionnaires comme Therry Steven dans FV ou Arcady Willy dans AD, gravitent autour du pouvoir les hommes d'argent comme Quentin Chamfort au début du siècle dans $A D$, ou des clans familiaux qui se chargent de récupérer les miettes du festin. Pour exemple, la famille Willy, dont la fille Malvina, indicatrice et tenancière de bordel est réputée être la fille du Président et dont le père officiel est l'homme de confiance du pouvoir. Les figures de ce type abondent.

Les symboles de la répression sont aussi désignés: la caserne Dessalines et Fort Dimanche sont des lieux de détention d'ou l'on revient rarement. Louis Vortex ou Damiens, dans FV en font l'expérience. Une autre technique de répression du citoyen consiste à le piéger. C'est le cas pour Sylvie Vortex dans FV victime de René Teril ou de Ludovic Vortex dans AD qui grâce à son sang-froid réussit à ne pas se faire arrêter pour la possession d'un fusil militaire qu'on a déposé dans son jardin.

Dans cette société aux abois, prise au piege de l'arbitraire, quelques contre-poisons sont mis en place. Le mariage (Hermes Désiré le militaire épouse une soeur du ministre Bonaventure), la notabilité (Solon Vortex échappe à l'arrestation grâce au sergent qui est son obligé), le sexe en sont des exemples. Le romancier fait une radioscopie des moeurs du pouvoir et d'une société qui de fait participe toute entière à un niveau ou à un autre à son propre asservissement.

\section{L'idéologie}

Certains cherchent un ressort idéologique pour sortir le pays d'une situation politique dont chacun sait qu'elle est tragique. Dans un pays désorganisé, résumé par cette phrase: «En Haiti, il n'y a pas de fonctionnaires, mais des agents de l'Etat, tous contractuels» $(\mathrm{AD}, 110)$.

Certains cherchent le sens. Sylvain Vortex représente la dimension idéaliste et poétique du discours politique: 
J'ai rempli les oreilles de mon peuple de promesses éclatantes! Et me voici au seuil de la victoire entre deux éteignoirs sans vision, sans passion. A toute foule sans pain, sans bénédiction et sans sacrement de cette terre d'Haïti, j'ai voulu apporter l'eau fraîche de la joie.... Dans tous les nids de l'espoir, j'ai couvé des mots puissants et souriants. J'ai illuminé les reliefs de l'ombre, émoussé les crocs du désespoir pour assurer la survie de mon peuple (FV, 233).

De fait, le point d'ancrage de tout discours sur Haïti reste la référence à 1804, date de l'indépendance haïtienne promulguée par Dessalines. Père de l'indépendance, il est aussi le seul à avoir eu une véritable dimension d'homme $d^{\prime} E$ tat prophétique et révolutionnaire. Son assassinat en 1806 , son parcours, sont source de réflexion dans toute l'oeuvre de Jean Métellus, il y consacre d'ailleurs une pièce de thêâtre Le Pont rouge. ${ }^{19}$

Louis Vortex, en exil découvre le communisme, grâce â son ami Régis Duffaud. Il étudiera Marx, Lénine, Plekhanov, avec la même ferveur que lors de son engagement chrétien. Mais bientôt, le communisme apparaît comme une impasse. Cette prise de conscience se fait brutalement au cours d'une conversation entre Louis et un représentant du parti.

[...] non pas que, dit Dussert avec insistance et bonne foi, que n'importe quel intellectuel ne puisse vraiment pénétrer ce systeme philosophique, mais parce que certaines structures mentales, résistent à certaines démonstrations. Si je comprends bien, dit Louis, le marxisme est une théorie à usage européen? (LV, 138).

Régis le militant, toujours «objectif dans la lutte» trouvera la mort à son retour d'exil en Haïti.

Louis Vortex, en pèlerinage au Fort de Joux où fut emprisonné Toussaint Louverture fait symboliquement le trajet du retour vers l'histoire haïtienne. Pour l'auteur, il ne fait aucun doute que c'est par la revisitation des grands mythes fondateurs de l'histoire haïtienne que le peuple pourra trouver sa voie. Toute son oeuvre en est l'illustration. Ainsi, Dessalines est aussi le héros caché du roman L'année Dessalines.

\section{Inventaire de l'exil}

Les personnages principaux de la saga des Vortex, sont contraints à l'exil comme par une sorte de malédiction: «Il y a deux types d'exilés. L'exilé qui ne s'insère pas. L'exilé en perpétuelle agitation et l'exilé qui s'enracine» (FV, 50).

Mythomanie, inquiétude, angoisse, délire de la grandeur ou de la persécution, toute la pathologie de l'exilé est présentée au travers des portraits des membres de la communauté haïtienne de Paris. Manie de l'écriture, manie du discours, réunions 
remplies de nostalgie, tous les exilés sont des chefs d'Etat en puissance. La chronique avance, entre humour et désespoir. Quelques notes d'humour soulignent les rapports entretenus avec les femmes européennes. De Louis Vortex, professeur dans une école catholique de filles en but aux fantasmes sexuels des mères et de leurs filles aux relations interraciales chaoteuses et chaotiques, Métellus, comme dans les romans d'Europe, fait une étude fine et singulière de la rencontre de deux mondes.

La saga des Vortex est un véritable univers, un monde avec ses lois et ses anarchies créatrices. Les trois romans forment une Comédie humaine balzacienne, plus cruelle que son modele.

\section{NOTES}

${ }^{1}$ La famille Vortex. (Paris: Gallimard, 1982); L'année Dessalines (Paris: Gallimard, 1987); Louis Vortex (Paris: Gallimard, 1992).

${ }^{2}$ Les dates de publication de ces deux derniers romans ne sont pas encore fixées.

${ }^{3}$ Nous avons choisi le terme de saga, terme à l'origine scandinave, pour caractériser ces trois romans qui racontent en effet l'épopée d'une famille, ici: la famille Vortex. Rappelons du reste, que le premier roman de Jean Métellus, Jacmel au crépuscule (Gallimard, 1981) fut traduit en néerlandais.

${ }^{4}$ Anacaona (Paris: édtions Hatier, 1985). Cette pièce conte l'histoire d'Anacaona, reine du Xaragua, l'un des cinq cacicats de l'île que les Taïnos appelaient Ayiti-QuisqueyaBohio. Cette reine fut la dernière résistante à l'invasion des Espagnols menée par Christophe Colomb en 1492. La pièce fut mise en scène par Antoine Vitez, à Paris, au thêâtre de Chaillot en 1988.

${ }^{5}$ Interview Media France Intercontinent avec Anne Blancard, 1982.

${ }^{6}$ Regis Antoine, «La littérature franco-antillaise, in Notre Librairie $\mathrm{n}^{\circ} 108$ (janviermars 1992), pp. 150-153.

${ }^{7}$ Balzac en effet, dans les romans de La Comédie humaine, en faisant structurer l'Histoire par la Sociéte, fut l'un des meilleurs techniciens de la création romanesque. Pour lui, comme pour Zola, il s'agissait au fond d'accomplir un travail de «condensation» (exprimer la vie de toute une société à travers le destin de quelques individus ou d'une famille). Doù chez Balzac l'importance de la métonymie: exprimer le tout par la partie. Un exemple en est donné dans la description de la pension du Père Goriot. Métellus use largement de cette technique, comme d'autres romanciers.

${ }^{8}$ Interview Média France Intercontinent.

'Interview, op. cit. 
${ }^{10}$ Lors de la proclamation de l'indépendance haïtienne par Dessalines le ler janvier 1804, sur la place d'armes des Gonaïves, certains Blancs détenteurs d'une technique (Médecins, ingénieurs...) furent en effect autorisés à avoir la nationalité haïtienne avec les mêmes devoirs que les Africains devenus Haïtiens. Ce fut le cas aussi pour certains soldats d'origine polonaise de l'armée napoléonienne qui refusèrent de se battre pour le rétablissement de l'esclavage à Haïti.

${ }^{11}$ Notons que Jean Métellus fut lui-même contraint à l'exil en 1959, dans des circonstances similaires, sa vie était menacée à cause de ses activités militantes au sein de L'UNMES (Union Nationale des Membres de l'Enseignement Secondaire).

${ }^{12} \mathrm{Du}$ nom de l'arène où se battent les coqs de combat.

${ }^{13}$ Le paysan haïtien est un personnage central de l'oeuvre de Jean Métellus, comme en témoigne son premier recueil poétique $A u$ Pipirite chantant publié en 1973 dans la revue Les Lettres Nouvelles de Maurice Nadeau, mais aussi le roman Les Cacos (Gallimard 1989) qui raconte la révolte des paysans haïtiens lors de l'occupation américaine d'Haïti de 1915 à 1934.

${ }^{14}$ Bernard Mouralis, Littérature et Développement (Paris: éditions Silex, 1984), p. 215.

${ }^{15}$ Interview accordée à A. Ntonfo, université de Yaoundé, le 14 mai 1987.

${ }^{16}$ Le président Jean-Bertrand Aristide fut élu le 7 février 1991.

${ }^{17}$ Interview Media France Intercontinent, avec Anne Blancard, 1982.

${ }^{18}$ Voir notamment le très beau roman $E l$ Reino de este mundo (Barcelona: editorial Seix Barral, 1969, première édition 1949) d'Alejo Carpentier situé en Haïti à la cour royale d'Henri Christophe. Voir aussi du même auteur El Siglo de las lucas (Barcelona: editiorial Seix Barral, 1965, première édition 1952).

${ }^{19}$ (Paris: éditions Nouvelles du Sud, 1991). La pièce commence au lendemain de la capture de Toussaint Louverture par traîtrise et son embarquement pour le Fort de Joux, et se termine sur l'assassinat Dessalines. 


\section{BIBLIOGRAPHIE DES OEUVRES DE JEAN MÉTELLUS}

\section{Poésie:}

Au Pipirite Chantant. Paris: Editions Maurice Nadeau, Lettres nouvelles, 1978.

Tous ces chants sereins.... Mareuil sur Mauldre: éditions Qui vive, 1980, épuisé.

Hommes de plein vent. Paris: Editions Silex, 1981. Réédité aux éditions Nouvelles du Sud, 1992.

Voyance. Paris: Editions Hatier, 1984.

Jacmel. Paris: Orénoques, 1991. Edition bilingue français-espagnol.

Voix nègres. Paris: Editions Le Bruit des Autres, 1991.

\section{Romans:}

Jacmel au crépuscule. Paris: Gallimard, 1981 (traduit en néerlandais).

La famille Vortex. Paris: Gallimard, 1982 (traduit en russe).

Une eau forte. Paris: Gallimard 1983.

La parole prisonnière. Paris: Gallimard, 1986.

L'année Dessalines. Paris: Gallimard, 1986.

Les Cacos. Paris: Gallimard, 1989.

Charles Honoré Bonnefoy. Paris: Gallimard, 1990.

Louis Vortex. Paris: Messidor, 1992.

\section{Théâtre:}

Anacaona. Paris: Editions Hatier, 1986.

Le pont rouge. Paris: Editions Nouvelles du Sud, 1991.

Colomb. Case Pilote (Martinique): Editions de L'autre mer. 1992.

\section{A paraître:}

Henri le Cacique

L'Ouverture-Les racines de la liberté 


\section{Essai:}

Haiti, une nation pathétique. Paris: Denoël, 1987.

Ouvrages Collectifs:

Négritude: traditions et développement. Bruxelles: Editions complexes, 1978.

Les Minorités dans la Pensée. Paris: Editions Payot, 1979.

40 écrioains parlent de la mort. Paris: Editions Pierre Horay, 1990.

Publications littéraires et poétiques (parues avant Au Pipirite chantant)

«Comme deux fantômes,» poèmes, in Les Lettres Nouvelles (juin-jillet 1969)

«Poèmes» in Les temps modernes (juin-juillet 1969).

Sous le pseudonyme de Philippe Decius:

«Hommes de plein vent,» «Pour, situer Haïti»» «Essai d'analyse structurale: Contes et réalités haïtiennes,» Europe (janvier 1971).

«Une affaire réglée,» Acoma $\mathrm{n}^{\circ}$ 4-5 (avril 1973).

«Poèmes,»Intégral (janvier 1974). 